\title{
A Model Eliciting Framework For Integrating Mathematics And Robotics Learning
}

\author{
David Nutchey \\ Faculty of Education, Queensland University of Technology, Australia \\ < d.nutchey@qut.edu.au >
}

\begin{abstract}
Robotics is taught in many Australian ICT classrooms, in both primary and secondary schools. Robotics activities, including those developed using the LEGO Mindstorms NXT technology, are mathematics-rich and provide a fertile ground for learners to develop and extend their mathematical thinking. However, this context for learning mathematics is often under-exploited. In this paper a variant of the model construction sequence (Lesh, Cramer, Doerr, Post, \& Zawojewski, 2003) is proposed, with the purpose of explicitly integrating robotics and mathematics teaching and learning. Lesh et al.'s model construction sequence and the model eliciting activities it embeds were initially researched in primary mathematics classrooms and more recently in university engineering courses. The model construction sequence involves learners working collaboratively upon product-focussed tasks, through which they develop and expose their conceptual understanding. The integrating model proposed in this paper has been used to design and analyse a sequence of activities in an Australian Year 4 classroom. In that sequence more traditional classroom learning was complemented by the programming of LEGO-based robots to 'act out' the addition and subtraction of simple fractions (tenths) on a number-line. The framework was found to be useful for planning the sequence of learning and, more importantly, provided the participating teacher with the ability to critically reflect upon robotics technology as a tool to scaffold the learning of mathematics.
\end{abstract}

Keywords: mathematics, robotics, model eliciting, number line

\section{Introduction}

There has been a variety of teaching and research activities at the intersection of mathematics education and robotics (or more broadly, technology education). The integration of mathematics and robotics curricula is the focus an ongoing research project titled 'ELLA Enhanced Learning through LEGO Activities'. In this paper, the first iteration of the ELLA project is reported upon, in which a class of Year 4 students in a typical Australian primary school were exposed to LEGO robotics and the technology was used to engage and scaffold the students' learning of fraction concepts, in particular tenths. What is novel to this research is the adaptation of the model construction sequence (Lesh et al., 2003) as the basis for designing and reflecting upon two parallel but complementary sequences of classroom activities: the regular mathematics lessons specified in a school curriculum and a sequence of robotics-based activities that were designed specifically to augment the regular mathematics lessons.

In the following sections, a brief review of pertinent literature that outlines the nexus of theory regarding mathematical modelling as a classroom pedagogy, robotics as a vehicle for learning and the analysis and description of mathematical knowledge and understanding is 
presented. This leads to the proposition of the conceptual framework, and in particular the proposition of the integrating model eliciting framework, underpinning this work. The frameworks application to the design and analysis of classroom activities related to the learning of fraction concepts is presented. Finally, some comments regarding the success of this first iteration and some implications for future iterations of the project are provided.

\section{Literature Review}

The ELLA project is aiming to develop pedagogical theory and practice regarding the use of robotics in the learning of school-level mathematics. This includes the development of theory or principles regarding learning activities and resources and exemplars of such theory activities. Central to this project has been the proposition of pedagogically driven conceptual framework that integrates three related conceptual bases: (1) mathematical modelling (Lesh et al., 2003; Lesh \& English, 2005); (2) constructionism (Papert, 1980, 1991); and (3) the genetic decomposition-based description and analysis of learners' knowledge and understanding (Nutchey, 2011a, 2011b). Each of these bases are now discussed in turn, from which the conceptual framework for the ELLA project is synthesised.

\section{Mathematical Modelling}

Bell (1993), amongst others, describes a model of mathematical problem-solving used by real-world mathematicians that can be thought of in three distinct and cyclical stages: (1) Mathematising; (2) Manipulating; and (3) Interpreting. Problem solving proficiency involves learners working with complex and unfamiliar situations and developing non-routine, or innovative, solutions and should be integral to a contemporary mathematics classroom. This is consistent with the view of Bell (1993), who, whilst recognising the importance of learning about problem solving and learning mathematics for problem solving (i.e., a more traditional applications approach), also stressed that increasing importance should be placed upon learning via problem solving. That is, learners should be challenged by real problems, ones for which there is no clear or obvious path to their solution. It is through such problem solving that a shift from "mathematics as computation" towards "mathematics as “conceptualisation, description and explanation” (Lesh \& English, 2005, p. 1) will be achieved and so develop within students the more complex and futures oriented view of mathematics which is needed for work in the 21st Century (Lesh \& English, 2005).

In more recent years, the term 'problem solving' is often been replaced by the term 'models and modelling perspective' or more simply 'mathematical modelling'. Galbraith (2011) provided a survey of the usage of this term, and has identified six different meanings or groupings of mathematics education research and practice. Galbraith suggested that of these (i.e., using real problems as a preliminary basis for abstraction, emergent modelling, modelling as curve fitting, and word problems) do not adequately address the need of 
developing conceptualisation, description and evaluation abilities. The fifth meaning associated with mathematical modelling is described by Galbraith as modelling as a vehicle. Galbraith adopts the term vehicle from the work of Julie (2002) to describe those cases in which a mathematical modelling activity is used with the "prime purpose of eliciting and consolidating new mathematical ideas” (Galbraith, 2011, p. 286). The sixth meaning of mathematical modelling described by Galbraith takes a very much process-oriented view, or modelling as content (Julie, 2002), which serves the "prime purpose of helping students to access and use their existing store of mathematical knowledge” (Galbraith, 2011, p. 286). In both these latter meanings, the mathematical model is conceived of as some conceptual structure that is constructed or used by the learner to make sense of experience.

Galbraith identifies the model eliciting work of Lesh and associates (e.g., Lesh et al., 2003) as a pedagogical tool that can be used to develop students' mathematical modelling (or problem solving) abilities, from both modelling as vehicle and modelling as real-world problem solving viewpoints. A sequence of model eliciting activities (MEAs) provides a way for learners to make explicit their developing ideas with regards to the problem at hand and their developing mathematical models. A significant aspect of Lesh et al.'s work is the belief that representational fluency - being able to flexibly express a mathematical concept in a variety of representational forms - is a significant factor that contributes to deep understanding. In terms of Bell's (1993) principles, this relates to the connectedness of the learner's developing organisation of mathematical ideas. Whilst model eliciting has a strong product focus (i.e., groups of learners working collaboratively on the solution of some problem), it is through such activities that the learners' conceptual understanding is revealed.

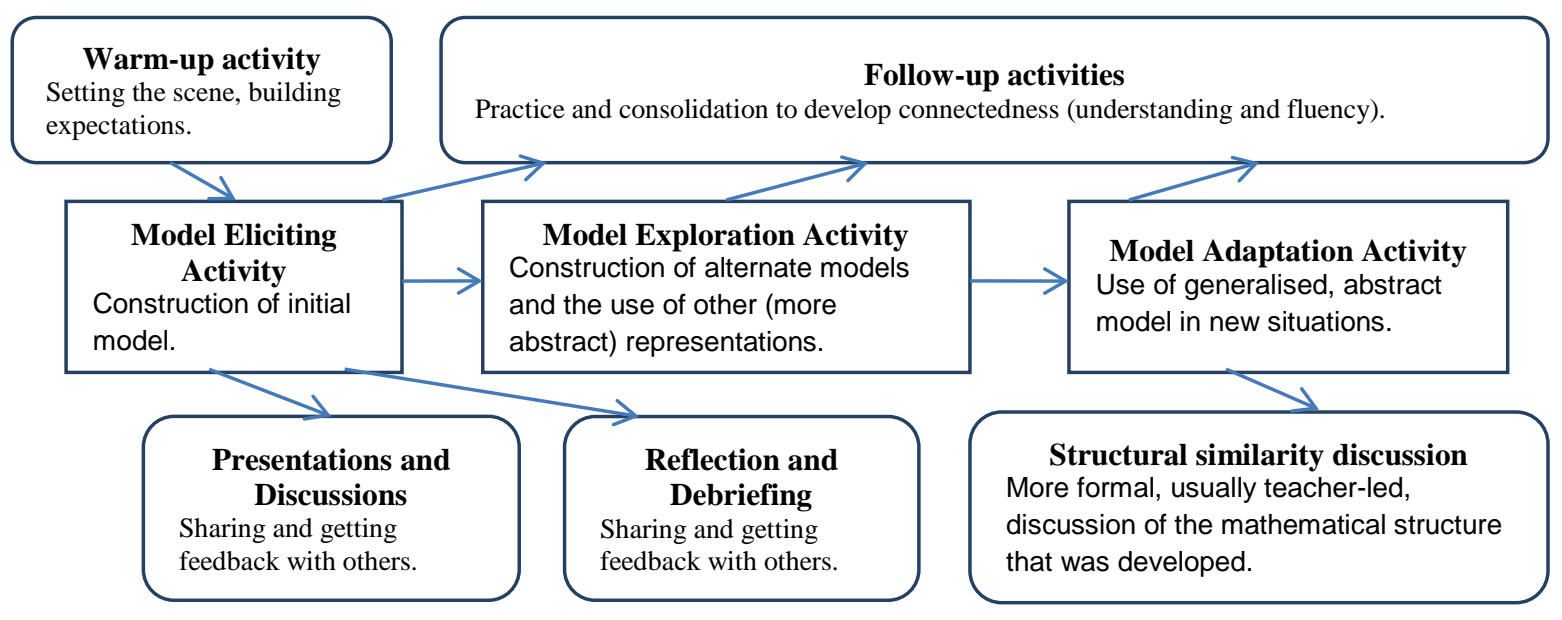

(adapted from Lesh at al., 2003, p. 45)

Figure 1. Lesh et al.'s (2003) model construction sequence

As suggested by the cycle of mathematisation (Bell, 1993), problem solving is rarely a simple one-pass process: multiple cycles of mathematical work often occur as learners (or any mathematician) either refine a solution or explore and compare a variety of solutions. This cyclical nature is accommodated by Lesh et al. (2003), who suggest that a single MEA should 
not be used in isolation. Instead, a sequence of model construction activities should be used (in combination with other classroom activities including practice activities aimed at developing or consolidating computational fluency). Such a sequence is described in Figure 1, which shows three model construction activities: the model eliciting activity, the model exploration activity and the model adaptation activity.

The model construction sequence thus embodies both modelling as vehicle and modelling as real-world problem solving meanings. In the sequence, the earlier model eliciting activity could be aimed at creating a new mathematical idea (i.e., the model). Then, further modelling activities (referred to as model exploration activities by Lesh et al.) provide opportunities for the learner to represent the mathematical ideas in different ways and to realise its connections to other mathematical ideas. Later in the sequence, the modelling activit(ies) aim to adapt the model to new situations that are different to those in which the model was originally developed. Thus, the model construction sequence provides a framework for explicitly applying, discussing and revealing how the mathematical concepts and processes constructed during the modelling activities relate to the overall structure or organisation of mathematics.

\section{Constructionism and LEGO ${ }^{\circledR}$ Robotics}

The seminal work of Seymour Papert and his constructionist theory (e.g., Papert, 1980, 1991) has been the basis of several educational technologies, including LOGO Microworlds, the SCRATCH visual programming environment for creating animations and games and the LEGO Mindstorms NXT robotics technology. Central to the constructionist theory is the premise that the use of technology to construct solutions to problems encourages peer-to-peer discussion and allows the teacher to observe the thinking that is going on as the 'product' is being designed, built and evaluated. That is, technology is a vehicle for learning which reveals the learners' thinking process(es) that lead to the product. When considered from a mathematics learning viewpoint, LEGO robotics provides learners opportunities to socially construct meaning related to concepts including: distance and angle measurement; time; whole, decimal and fractional number notation; geometric shapes and reasoning; rate, ratio and proportional relationships and the associated reasoning required to solve equations; and the development and management of multi-step solutions.

\section{Graphical Representation of Knowledge and Understanding}

Nutchey (2011a, 2011b) has proposed genetic decompositions as a graphical way in which to describe both the structure of mathematical knowledge shared in a community and the understanding that an individual has of that knowledge. This work is a synthesis of Popper's (1978) three-world conceptualisation of knowledge and Piaget's notion of reflective abstraction (Dubinsky, 1991; Piaget, 2001). Genetic decompositions identify the set of 
knowledge objects (the problems, concepts and representations of the domain) as well as the reflective abstraction-based knowledge associations. Together, these constructs can be used to weave together a complex description of the knowledge in some mathematical domain. For the reader's reference, a summary of the graphical language's constructs used to create genetic decompositions is presented as an appendix. Additionally, Nutchey has conceptualised understanding in terms of the sequence of experiences that a learner has as they explore the structure of shared mathematical knowledge. Quite literally, the implication for instruction is that learning experiences should be designed such that the learner has the opportunity to encounter all connections in the organisation of mathematical ideas, such that they too construct the meaningful associations which link together problems, concepts and representations.

\section{Conceptual Framework}

Mathematical modelling necessitates a context that is accessible and from which learners can develop intuitive through to formal understanding. It is the premise of this research project that LEGO-based robotics provide such a context in which mathematical modelling can be conducted. Moreover, LEGO-based robotics activities can be carefully designed so that learner's are scaffolded and directed in their exploration the structure of shared mathematical knowledge, either to elicit new mathematical ideas or to consolidate existing mathematical ideas. To organise learning activities to achieve such a scaffolding, a variant of Lesh et al.'s model construction sequence has been proposed and is illustrated in Figure 2. This so called integrating model eliciting framework explicitly sequences regular mathematics lessons with ELLA activities in a zig-zag fashion, such that the more typical mathematics lessons provide the opportunity to prelude and/or follow up the mathematical content of the activities in the ELLA model construction sequence (and vice versa). As with Lesh et al.'s original model, the sequence of ELLA modelling activities progressively expand upon the mathematical model used by the students, firstly eliciting the model, then exploring its use and finally adapting it for new uses. As a model of both curriculum integration and research design, the middle activity design section refers to not only the design of LEGObased activities to complement the regular mathematics lessons, but also the ongoing research-teacher dialog that features in the ELLA project. Using the proposed integrating model eliciting framework it is the goal of the ELLA project to explore how the use of LEGO-based mathematics model eliciting might provide contribute to the more innovative and futures-oriented interpretation of "mathematics as conceptualisation, description and explanation” (Lesh \& English, 2005, p. 1). 


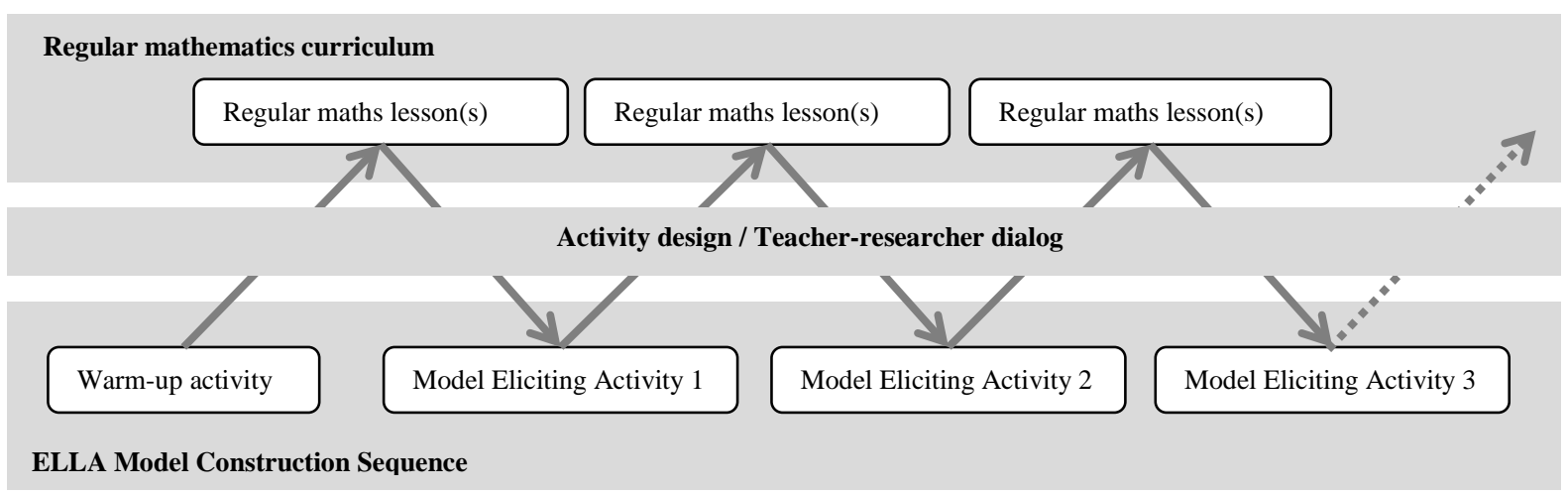

Figure 2. Proposed integrating model eliciting framework

\section{Methodology}

Complementing the design-based problem solving approach to learning mathematics, the ELLA project has adopted a three-tiered teaching experiment methodology in a similar way to Lesh et al.'s own work in the study of model eliciting (Lesh \& Kelly, 2000). The ELLA project has considered three tiers: the researcher's developing understanding of LEGOß-based modelling activities; the teacher-participants' use of LEGO ${ }^{\circledR}$-based modelling activities to inform evidence-based teaching design; the student-participants' developing knowledge and understanding of mathematics, including their proficiencies and content knowledge. Each tier of the teaching experiment can be considered as an iterative, longitudinal study: At each cycle of study, the developing theory used to explain the observations at each level is refined and fed into the next cycle of research.

In this paper, the first iteration of ELLA is reported upon. The participants in this iteration were a class of 26 mixed ability Grade 4 students (aged 9-10 years) in a typical Australian primary school. Their teacher also participated in the iteration; whilst having no substantial prior experience with LEGO robotics, she actively contributed to the design and delivery of the ELLA learning activities, as well as teaching the regular mathematics lessons. This teacher input is central to the ELLA project and the proposed integrating model eliciting framework: the LEGO activities were designed to align to the regular mathematics lessons and to match the specific learning needs of the student participants. Data gathered during the iteration included: student generated artefacts from the robotics sessions (e.g., completed worksheets), teaching plans associated with the regular mathematics lessons (i.e., mathematics teaching and learning that occurred away from the robotics sessions) and field notes of the researcher that reflected upon the robotics activities and the discussions that occurred with the teacher both before and after the ELLA sessions. This data was then analysed to identify the mathematical ideas encountered by the learners in both the regular mathematics and ELLA activities. This analysis was guided by Nutchey's (2011b) knowledge modelling technique and genetic decompositions for both regular mathematics lessons and ELLA activities were created. These genetic decompositions served as a basis for comparing 
the regular mathematics and ELLA activities, with the view to identifying potential opportunities for improving the teaching and learning of fraction knowledge in an integrated fashion using the proposed model eliciting framework.

\section{Data and Analysis}

The iteration of the ELLA project teaching experiment reported upon in this paper was conducted over a month long period in which students participated in four ELLA sessions. Each week the students (working in small groups of 2-3) participated in 70 minute sessions in which they worked on completing different ELLA activities that complemented their regular mathematics curriculum. This particularisation of the integrating model eliciting framework to this iteration is illustrated in Figure 3. The focal mathematics concepts developed during this period included: the construction of fractions using various concrete materials; expression of the fractions using both common fraction (mixed and improper) and decimal notation; the use of a number-line model to represent the relative size, position and equivalence of fractions; and counting by fractions and associated rudimentary addition and subtraction strategies for fractions, in particular tenths;.

In the following sub-sections, the mathematical content explored in the regular mathematics lessons and the activities of the ELLA model construction sequence are summarised and their contribution to the participating learners' development of understanding is discussed. The mathematical ideas experienced (and so potentially understood by the students) have been analysed and described using the genetic decomposition technique.

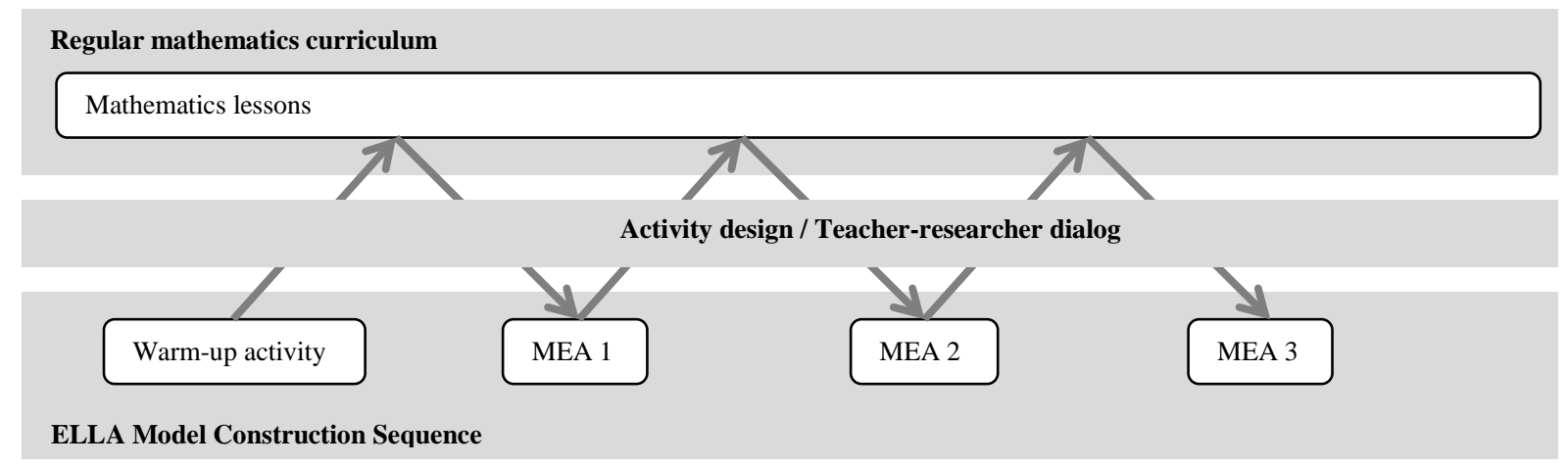

Figure 3. Particular instance of the integrating model eliciting framework

\section{Regular Mathematics Lessons}

In the new Australian Curriculum: Mathematics (ACARA, 2012), Year 4 students are expected to study fraction related ideas including: investigating equivalent fractions used in context; count by quarters, halves and thirds, including mixed numbers, and be able to locate these numbers on a number line; extend the place value system into tenths and hundredths; and make connections between decimal and common fraction notation for fractional numbers. 
Many of these ideas were developed, often at an introductory level, during the lessons related to this study. During the regular mathematics lessons, the teacher followed a curriculum designed by the state-level public school organisation; the teacher was free to adopt or adapt the materials provided in this curriculum to suit the specific needs of the students, and for the most part the sequence of instruction specified in this state-level curriculum was adhered to.

\section{Lesson sequence}

The regular lesson sequence (approximately eight 60 minute sessions) began by using an area model-based approach to the construction of fractions: The children performed activities such as folding a piece of paper to get halves, and then refolding to get quarters and eighths. The equal area of each part was stressed to highlight that the partitioning of a whole into fractional parts requires each part to be of the same size. In addition to the concrete representation of fraction, the symbols (e.g., $1 / 2$ ) and the literal names (e.g., one half) were also introduced and linked to each of the fractions created. A similar approach using length model-based paper strips was used to also construct half, quarter and eight sized paper strips. To reinforce the idea that the size of a fraction is not absolute but instead proportional to the size of the whole, different sized 'whole' pieces of paper and paper strips were used. In a related way, it was discussed that as the number of parts increased, the size of those parts decreased. Terminology such as denominator (the name of the part) and numerator (how many of the parts) were also used when discussing the fraction activities. Once halving strategies were soundly developed, alternate partitioning strategies, such as by thirds and by fifths, were introduced to develop a range of fractions including sixths, tenths and fifteenths.

Counting by fractions was then introduced. Students began by counting in halves, using both improper fractions (e.g., 5 halves or $5 / 2$ ) and also mixed numbers (e.g., two wholes and one half or $21 / 2$ ). To scaffold this, the number line was used to locate each of the two forms of fractional number and so identify their equivalence.

The relative size of fractions was also considered; the paper strip fractions constructed using various folding strategies (partitioning to halves, thirds fifths and combinations thereof, and all beginning with the same sized whole) were compared with each other, both to identify relative size and also to identify fractions that were equivalent (e.g., $1 / 5$ is equal to $2 / 10$ ).

With the previously developed understanding of partitioning, fraction equivalence and fractional numbers bigger than one, students then returned to a more detailed study of tenths. The students counted in tenths, represented number using improper and mixed number forms and used the renaming strategy to convert between improper and mixed number forms. Number expanders were used to scaffold the students' use of improper and mixed number forms. Decimal notation was then introduced as an alternative symbolic representation. Just as students previously counted using common fraction representations of tenths, students then used decimal fraction representation to count along number lines in tenths, which was further 
extended to counting in other patterns, such as two tenths (0.2) and five tenths (0.5). This counting by tenths provided a basis for rudimentary addition and subtraction by tenths using a count all-like strategy (similar to that they would have encountered when first learning whole number addition).

\section{Genetic decomposition of lesson sequence knowledge}

A genetic decomposition that summarises the organisation of mathematical knowledge experienced by the students during the regular lesson sequence is shown in Figure 4. This genetic decomposition is only partial: it identifies the problems (tasks) encountered during the lesson sequence and the coordination of mathematical concepts used to solve these problems - the genetic decomposition does not describe the various representations used by the students to express the problems or concepts.

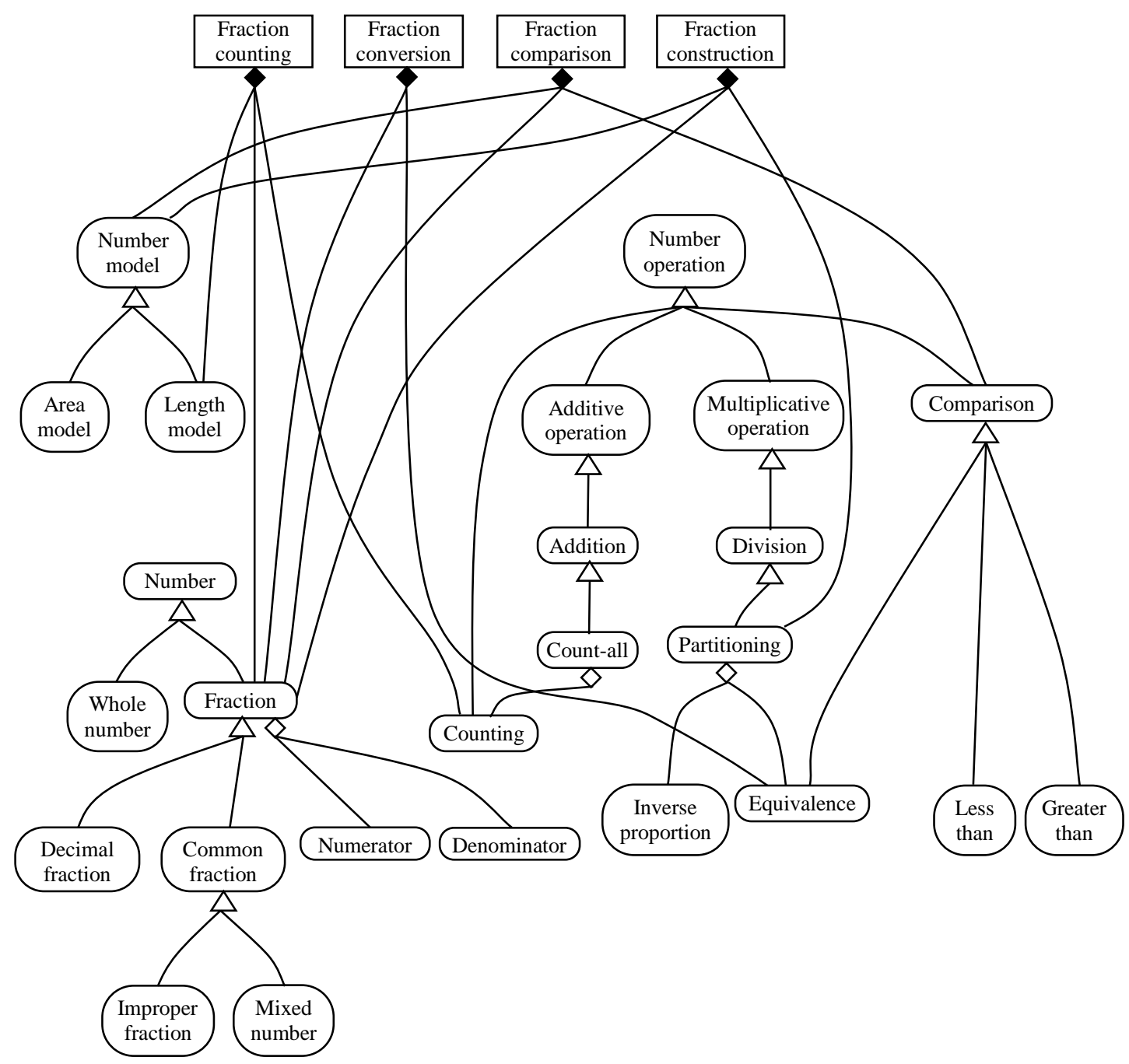

Figure 4 Genetic decomposition of the knowledge covered in the regular mathematics lessons 


\section{LEGO-Based Model Construction Sequence}

In the LEGO-based model construction sequence, the ultimate aim was to use a simple three-wheeled robot, called the Tribot, and program it to 'act out' relatively simple addition and subtraction problems using tenth operands.

\section{Warm-up activity}

In the warm-up activity (aimed at familiarising, engaging and enthusing students to participate in the ELLA activities), each small group followed a set of picture-based instructions to construct the Tribot'. This warm-up activity not only familiarised the students with the LEGO NXT technology, but provided the teacher and researcher opportunity to observe group work skills and identify students who might potential struggle to make sense of the technology. By the end of this session, all groups had successfully constructed their robot.

\section{MEA 1}

In the first MEA, the students were introduced to programming the robot, and were challenged to program the robot to travel a prescribed distance in a straight line. The bigger aim of this MEA was to scaffold the students' connection of the robot's straight line movement to their prior experience of the number line model - that is, to elicit the number line model in this new setting.

Four marks were put on the floor in a straight line and (unknown to the students) these marks were spaced a distance corresponding to exactly 10 wheel rotations of the robot. The students were then challenged to determine how many wheel rotations were required to move their robot exactly from one mark to the next. They quickly established that ten wheel rotations were required. That is, they applied the process of quotitioning-like division to establish how many wheel-rotation sized parts were in the whole. A whole class discussion then ensued to realise the number-line nature of the marks on the floor, with various positions along the number line being identified (e.g., 1 whole, 1 whole and 5 tenths, 2 wholes, 3 wholes, one half) and also what the equivalent tenth fractions were (e.g., 10 tenths, 15 tenths, 20 tenths, 30 tenths, 5 tenths)

\section{MEA 2}

In the second MEA the number-line model used to describe the robot's movement was explored in more detail. Also, the students were introduced to multi-step programming (i.e., programming a sequence of robot moves) so that they would be able to make the robot traverse the number-line in a series of jumps.

After reviewing the previous MEA and the notion that one wheel rotation was equivalent to one tenth of the distance along the number line, the students were given a worksheet prepared by the teacher. The first question was quite direct: it gave explicit instruction regarding where the robot was to start, and how many and what direction the 
Tribot's wheels should rotate, i.e., "Start at 0 on the number line, move forward 15 rotations, reverse 3 rotations, move forward again another 8 rotations, where on the number line do you end up?” The next question was similar in structure but, instead of specifying the instructions in number of wheel rotations, the Tribot's movement was specified in the movement of tenths on the number line, i.e., "Your starting point is at 2. Reverse back 0.6, move forward 1.2, reverse again 0.6. What is your end point?”. The final questions of the worksheet were more open ended, giving the students start and end point and asking them to determine suitable instructions e.g., "If I start at 1.5 on the number line and I want to get to 2.5 can you provide three instructions to get there?”

\section{MEA 3}

In the final MEA of the sequence, a larger number line (i.e., 10 wholes) was constructed. Each group was given a set of 10 question cards. The questions ranged in difficulty and covered tenth-based addition, subtraction and equivalence. The answer for each question formed the argument to a 10-step program the students wrote to traverse the large number line (i.e., on each question card, the students were instructed to program the robot to move either forward or backwards by the unknown amount). On the worksheet provided to the students, a 0-10 number line was provided and students were asked to not only write the 10 -step program but also to predict/calculate where their robot would finish. Thus, this MEA provided an opportunity for the students to adapt their number-line model of the robot's movement to a somewhat different context.

Genetic decomposition of ELLA model construction sequence knowledge

A genetic decomposition that summarises the organisation of mathematical knowledge experienced by the students during the ELLA activities is shown in Figure 5. It shows how the students actively engaged in problems requiring them to construct, compare, convert, add and subtract fractions. In each of these tasks, the students drew on a similar set of concepts (compared to their regular mathematics lesson activities), except that instead of partitioning, quotitioning was the process by which the fractional positions along the number line were constructed. Also, because the instructions for programming the robot were often specified in terms of the addition and subtraction problems, new strategies such as count-on and countback were evidenced in the students solving of these problems. As with the analysis of the regular mathematics lesson sequence, this genetic decomposition does not describe the various representations used to express the mathematical problems and concepts. 


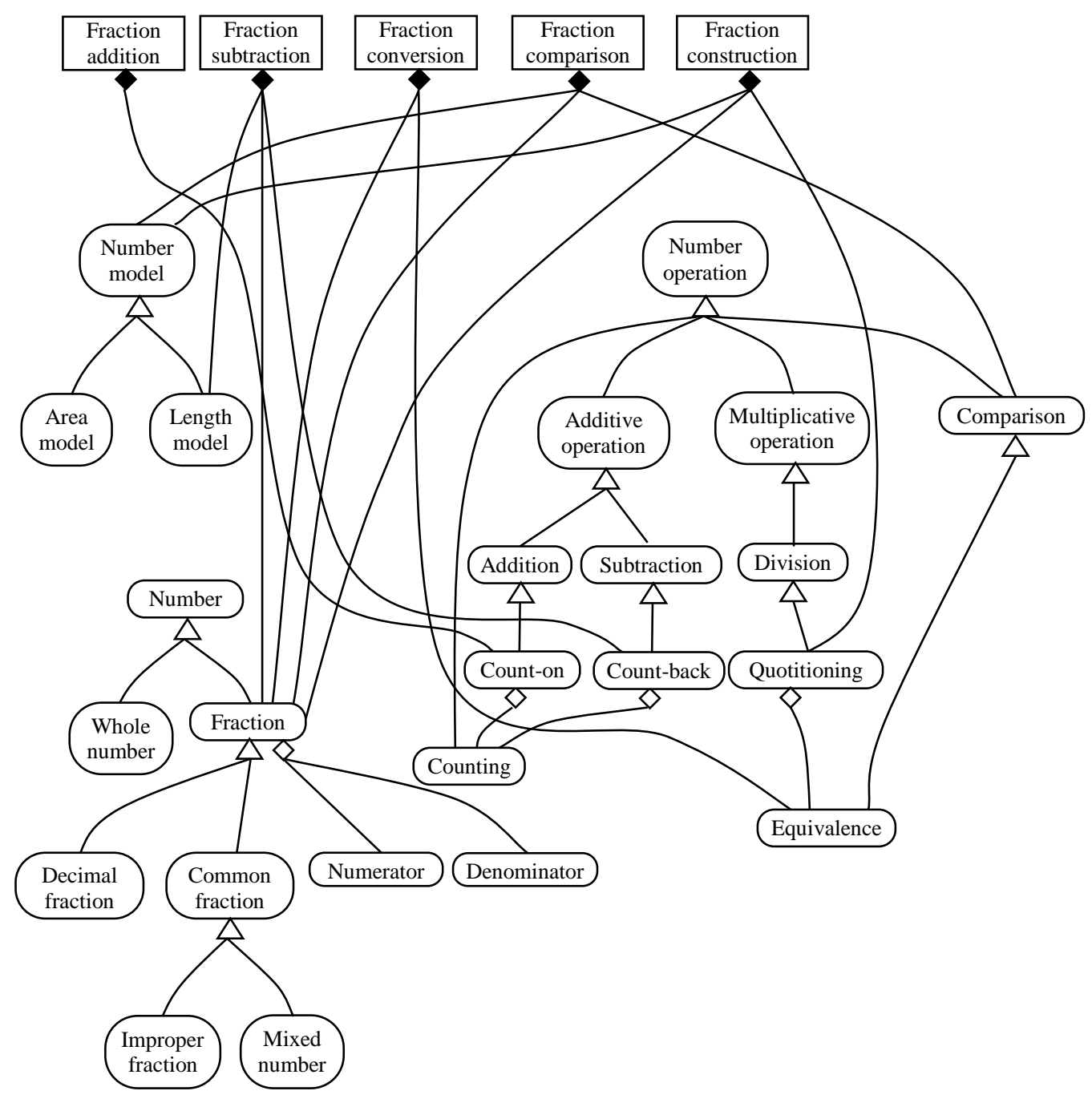

Figure 5. Genetic decomposition of the knowledge covered in the LEGO-based model construction sequence

\section{Implications and Conclusion}

The ELLA project is aiming to develop theory and exemplary practices of how LEGO-based activities, in particular those using robotics, can be used in an integrated manner to develop students' understanding of mathematics. The first iteration of this project has demonstrated the viability of the proposed integrating model eliciting framework as a pedagogical approach to bring together mathematics and technology/ICT curricula.

Upon reflection and discussion, both the researcher and teacher involved in this iteration feel that the zig-zag nature of the integrating framework has allowed the robotics activities to be carefully and strategically designed and inserted into the sequence of activities that have contributed to the learners' mathematics understanding. The regular lesson and ELLA activities have been complementary, both in the sense that one has provided opportunity to consolidate the learning of another and also in the sense that one has provided opportunity to introduce new concepts not covered in the other. A particular example of this 
is the notion of quotitioning which is an important form of multiplicative (division) thinking and which was not covered in the regular lesson sequence.

The constructionist theory underpinning the LEGO robotics technology has been very evident during the ELLA sessions: students were actively engaged in discussing the robot's movement, both through verbal language and also through the use of mathematical representations such as the number line to predict and/or troubleshoot the robot's movement. The use of the number line model, both on paper and as the 'track' along which the robot moved was very telling of the students' thinking with regards to fractions. Some students' use of the number line model indicated their beginning understanding of fraction counting, addition and subtraction, since they resorted to marking every movement by a tenth on the number line (or their robot only ever moved 1 wheel rotation at a time). Other students, with a more sophisticated understanding of fraction addition and subtraction, were able to show the robot's movements as jumps on the number line and their robot moved in similar ways. Such feedback to the teacher is invaluable in ascertaining learner understanding and to tailor instruction to leverage current understanding and address misconception.

Whilst this first iteration of the ELLA project has been successful, it has identified opportunities for further enhancement of the research methodology and the ELLA activities. The integrating model eliciting framework has been presented as complementary and tightly connecting regular mathematics lessons and robotics activities. From a research methodology as well as classroom practice perspective this could be further strengthened. Greater detail regarding the student's activity in their regular mathematics lessons would allow for much better design of LEGO activities that are timely and relevant to the students' learning. This is as much an issue of research technique as anything else. One way in which this could be improved is more accurate record keeping by the teacher as to what activities (and conceptual challenges they caused) were conducted during the mathematics lessons. Also, this requires an ability to quickly design and prepare/adapt LEGO activities that are of immediate relevance. In a related way, more detailed analysis of the mathematical knowledge and anticipated learning needs to occur before instruction, because this will better inform the design of both the regular classroom activities and the ELLA activities. For example, it was during the post-sequence data analysis that the difference between division strategies (partitioning vs. quotitioning) was identified. Similarly, a greater alignment between the preaddition (counting) activities of the regular mathematics lessons and the programming of the robot could have been achieved by simply including programming tasks such as making the robot act out fraction counting patterns.

The research activity presented in this paper has proposed a novel adaptation of the model eliciting framework that might allow for a closer integration of mathematics and ICT curricula, with the view to using robotics as a resource to more effectively teach mathematics. Whilst only in its infancy, the data gathered thus far has shown how even young students are 
able to use the technology, and that through its use the students application and elicitation of mathematical concepts has been strong. Importantly, the nature of the ELLA tasks has necessitated students to discuss their developing understanding of the embedded mathematical concepts, which has not only contributed to their deeper understanding but has given the teacher (and researcher) valuable insight into the students' mathematical thinking.

\section{Appendix - The Graphical Language}

Knowledge objects - the three different types of knowledge objects are used to identify the different mathematical ideas in some domain of knowledge

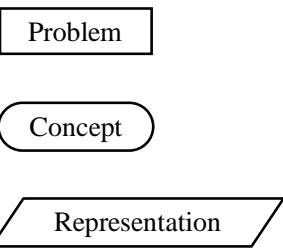

The problem object describes a problem, or task, that might be encountered when engaging in mathematical activity The concept object describes some process, concept or principle used when conducting mathematical activity

Representation The representation object describes some way in which a mathematical problem or concept might be expressed.

Knowledge associations - drawing on Piaget's notion of reflective abstraction, the different associations describe the cognitive mechanisms by which the organisation of knowledge is formed.

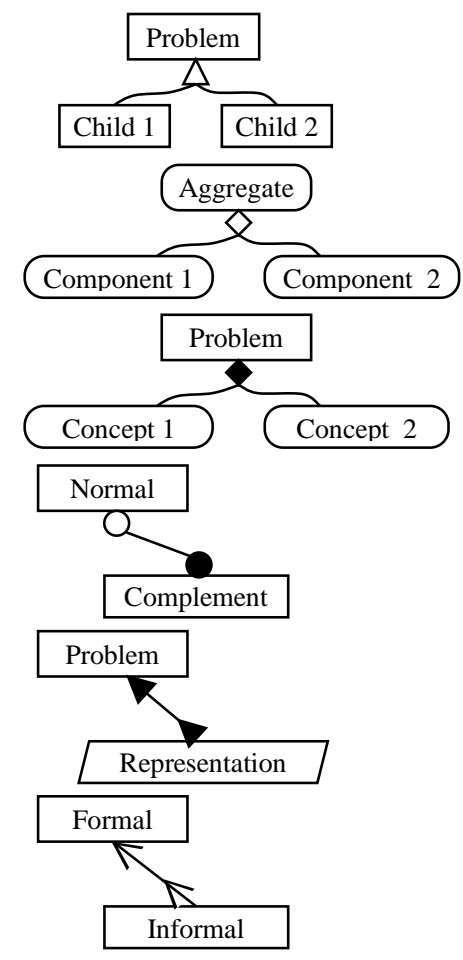

Inheritance describes a super-ordinate relationship between an abstract parent and one or more children, and can be applied to problems, concepts and representation objects.

Aggregation describes an aggregate object composed of one or more component objects, and can be applied to problem, concept and representation objects.

Solution describes a problem being solved using a coordination of one or more concepts.

Inversion describes one object (the normal object) having an inverse (the complement object). This association can be applied to problems and concepts.

Expression describes the expression of either a problem or concept using a representation object.

Formalisation describes one representation (the formal representation) to be more abstract than another (the informal representation). 


\section{References}

Australian Curriculum Assessment and Reporting Authority (ACARA). (2012). Australian Curriculum: Mathematics ver. 3.0.Canberra: Author

Bell, A. (1993). Principles for the design of teaching. Educational Studies in Mathematics, 24(1), 5-34.

Dubinsky, E. (1991). Reflective abstraction in advanced mathematical thinking. In D. Tall (Ed.), Advanced mathematical thinking (pp. 95-123). Dordrecht/Boston/London: Kluwer Academic Publishers.

Galbraith, P. (2011). Models of modelling: Is there a first among equals? Paper presented at the 34th Annual Conference of the Mathematics Education Research Group of Australasia.

Julie, C. (2002). Making relevance relevant in mathematics teacher education. Paper presented at the Proceedings of the Second International Conference on the Teaching of Mathematics (at the undergraduate level).

Lesh, R., Cramer, K., Doerr, H., Post, T., \& Zawojewski, J. (2003). Model development sequences. In R. Lesh \& H. Doerr (Eds.), Beyond constructivism: Models and modelling perspectives on mathematics problem solving, learning and teaching (pp. 35-58). Mahwah, NJ: Lawrence Erlbaum Associates.

Lesh, R., \& English, L. (2005). Trends in the evolution of models and modeling perspectives on mathematical learning and problem solving. ZDM: The International Journal on Mathematics Education, 37(6), 487-489.

Lesh, R., \& Kelly, A. (2000). Multitiered Teaching Experiments. In A. Kelly \& R. Lesh (Eds.), Research Design in Mathematics and Science Education (pp. 197-230). Mahwah, NJ: Lawrence Erlbaum Associates.

Nutchey, D. (2011a). A Popperian consilience: Modelling mathematical knowledge and understanding. Paper presented at the 34th Annual Conference of the Australasian Mathematics Education Research Group, Alice Springs, Australia.

Nutchey, D. (2011b). Towards a model for the description and analysis of mathematical knowledge and understanding. (PhD), Queensland University of Technology, Brisbane, Australia.

Papert, S. (1980). Mindstorms: Children, computers and powerful ideas. New York: Basic Books.

Papert, S. (1991). Situating constructionism. In I. Harel, S. Papert \& Massachusetts Institute of Technology Epistemology and Learning Research Group (Eds.), Constructionism: Research reports and essays, 1985-1990 (pp. 1-12). Norwood, NJ: Ablex Publishing Corp.

Piaget, J. (2001). Studies in reflecting abstraction (R. Campbell, Trans.). Sussex, England: Psychology Press.

Popper, K. (1978). Three worlds. Retrieved from http://www.tannerlectures.utah.edu/lectures/documents/popper80.pdf. 